\title{
Strategic Analysis of the Catering Industry under Covid-19: a Case Study in China
}

\author{
Xiaoxiao Xiong ${ }^{\dagger 1, a}$, Ruoyu Yao ${ }^{\dagger 2, \mathrm{~b}}$ \\ ${ }^{1}$ School of business The University of Queensland Brisbane, Australia \\ ${ }^{2}$ International department The high school affiliated to Xi' an Jiaotong University Xi' an, China \\ ${ }^{\dagger}$ These authors contributed equally.
}

\begin{abstract}
In the normal phenomenon, the restaurant industry strategic planning and future development trends are diverse, therefore, it is difficult to choose for. Existing literature does not provide effective guidance for the implementation of strategic plans in the catering industry under coVID-19. Taking RJ Restaurant in Chongqing as an example, this paper uses the method of combining qualitative and quantitative methods to study the difficulties that restaurants are facing now. This study clarifies that at the strategic level, the belief of medium-sized private restaurants to survive coVID-19 needs be based on identifying their deficiencies to establish cost strategy and differentiation strategy, which includes emphasizing the future development trends of intelligent use and "customized" services. There are two contributions to this study. First of all, this study provides a stereotyped municipal infrastructure framework for the study of private restaurants. In addition, this study studied the literature on strategic analysis of the catering industry from the perspective of coVID19.
\end{abstract}

\section{INTRODUCTION}

At the end of 2019, the number of patients with pneumonia of unknown cause was increasing in some medical institutions in Wuhan. Subsequently, in January 2020, a new virus, COVID-19, which causes human-to-human transmission, was discovered. Due to the rapid and intense coVID-19 spread, China's real economy industry has suffered a huge impact. To prevent the spread of the epidemic, China has closed roads, closed buses and closed entertainment venues within a short period. This has not only led to the shutdown of Chinese factories, the loss of retail, catering and hotel tourism by trillions of dollars, but also caused the price of vegetables to rise sharply and the supply of food materials to be in short.

The western economics and management circles promote the development and innovation of enterprise competitive strategy theory through competitive strategy theory, which wins the international competitive advantage for enterprises or groups and lays the academic position of enterprise competitive strategy theory. With the evolution of the economic system, enterprises have gradually changed from the former government subsidiary to the market independent subject, and the demand for competitive strategies of enterprises is increasing day by day. Since the 1980 s, the theory of competitive strategic management of enterprises has gradually formed three mainstream schools, namely, the configuration school, the competence school and the resources school [1].

In short, Andrew Andrews, the founder of SWOT analysis, can be regarded as a representative of the structural school. And the famous American strategic manager, Professor Michael Porter of Harvard Business School also has a long history of relevant research on the theory of new enterprise competitive strategy. He has repeatedly stated that "structural analysis is the cornerstone of competitive strategy" and that "understanding industrial structure is always the starting point of strategic analysis" [2]. His Porter's five forces competitiveness determines the competitive intensity and ultimate profit potential of an industry and makes industrial choices through competitive strategies. In addition, Porter also published another important aspect of enterprise war strategy theory competitor theory analysis model, how to identify and analyze competitors and how to grasp competitors' market action signals [3]. These analytical skills have strong operational significance and practical pertinence.

The competence school is due to the limitations of Porter's competitive strategy theory. The industrial structure is a key part of the competitive environment of an enterprise. Although Porter's theory starts with the industrial structure and makes a thorough analysis of what an enterprise may do, it fails to accept in detail what an enterprise can do. The competitive strategy and theory of the competence school, which is based on the production and operation behavior of the enterprise and the unique ability in the process, make the enterprise become a competitor based on the ability [4]. The core competence view represented by Hamel and Prahalad and the overall competence view represented by Stack, Evans and Shulman are the most representative. Both views

$\overline{\text { a1523823224@qq.com b2250336153@qq.com }}$ 
emphasize the unique capabilities embodied in the internal behaviors and processes of the enterprise. The former focuses on the individual key advantages in the enterprise value chain, while the latter emphasizes the overall advantages in the value chain [5].

Part of the theoretical viewpoints of the resource school appeared in the mid-1980s. After 20 years of rapid development, it has basically become the dominant school of theory in the field of enterprise competition strategy research. Emphasizing the importance of the resource problem is the starting point and foundation of the theory of resource school. If an enterprise wants to achieve good results, it must develop a series of unique competitive resources and allocate them to the proposed competitive strategy. Collins and Montgomery, the main theoretical representatives, believe that the evaluation of resource value should not be limited to the enterprise itself, but should place the enterprise's resources in the industrial environment it faces, and judge its advantages and disadvantages by comparing the resources owned by its competitors [6]. After that, British scholars Faulkner and Bowman further expanded the theoretical system and analytical model of resource-oriented competitive strategy [6]. What they created: the Customer matrix, a twodimensional matrix of perceived variables called price and perceived use value, and the Producer matrix, where the vertical axis represents the effective capacity to generate value and the horizontal axis represents relative unit cost, provide a fairly accurate grasp of an enterprise's competitive position in the market.

To sum up, the current theories aim to analyze and make decisions for large enterprises, which are too vague for urban catering businesses. And there is no strategic analysis of coVID-19 related to an irresistible external factor. Therefore, this paper will take RJ restaurant as the research object, conduct a comprehensive analysis through the internal and external environment, and summarize the development advantages and defects of the company. To help RJ restaurant take effective measures in the face of coVID-19, plan the development direction of RJ Restaurant, and finally meet the requirements of the strategic development goal - to make RJ restaurant survive in this specific environment.

\section{DATA}

Chongqing RJ restaurant is a medium-sized restaurant owned by Chongqing QJ Group, featuring seafood, freshfrozen seafood, game and Jianghu cuisine. The restaurant was established in August 2017 and officially opened in January 2018. RJ restaurant covers a total area of 2200 square meters, with a total of 8 business rooms (the average area is 30 square meters); There are 5 VIP rooms (with an average area of 75 square meters) and a hall of 1,300 square meters, which can accommodate 50 tables for banquets. There is enough space for banquets, weddings, birthday parties and school reunion. Two 45-square-meter mahjong parlors are available for guests to use to the greatest extent possible to meet the mahjong culture of Chongqing.

The restaurant has its own Foton ice fresh car, which is worth about 130,000 RMB. It uses two compressors and two systems and a USES temperature control instrument and an automatic electronic distribution system to rationally distribute the refrigerated car's cooling capacity and the cab air conditioner. Moreover, it has low fuel consumption, low noise, low cost, simple installation and convenient use. All the seafood is shipped from Beihai by Futian Ice truck. With "oxygen pump + water" preservation technology, seafood can be kept alive for up to 30 hours. Beihai's journey to the restaurant takes 15 hours and 40 minutes, overcoming the difficulty of inland China in returning fresh seafood, which is more important than frozen in taste. In addition to the seafood preservation counters, professionals mix the proportion of water and salt to extend the life cycle of live seafood. On average, the trucks make three or four trips a week to maximize the daily consumer's enjoyment of live seafood.

RJ restaurant is located in Beibin Road, which not only faces a better river view, but also attracts more consumers under the atmosphere rendering of the food street. So, there is a large flow of people during middle and evening meals. Secondly, RJ restaurant is located in the commercial shop of Building 3, QJSC, a high-end residential area. There are enough spacious free parking Spaces outside the restaurant, which not only broaden the user base but also provide convenience to consumers to a greater extent. The restaurant features high-end catering routes, the design of the new Chinese style as the theme, restaurant design positioning, and the enterprise's operation is closely linked.

RJ serves three of China's eight major cuisines: Sichuan, Guangdong, Hunan and the local Jianghu cuisine. The variety of dishes and the proper combination of nutrition, the innovation in tradition and the wide coverage (from banquet dishes to home-style dishes) make the dishes of RJ restaurant rich and diverse. In addition to the price of a single order, the restaurant also has five set meals at different prices, which cater to the dietary needs of different consumer groups. It can produce fine and inexpensive food and produce a feast enjoyed by high-end consumers. So, you have more market share. Although RJ restaurant is located outside the senior residential area and close to Binjiang Road, the shop directly under QJ Group saves a large amount of rent, reduces operating costs, and increases profit space.

At the present stage, the operation mode of $\mathrm{RJ}$ restaurant is still dominated by offline applications, and a series of online operation activities, such as introducing the restaurant and dishes, are just in the initial stage. Since the outbreak of the epidemic, online trading has sprung up according to the current demand and development. Combination of public comment, hungry (China's leading local life information and trading platform, to provide users with preferential merchant information, reviews and consumption such as information service, at the same time offer deals, restaurant reservations, takeout, and trading services such as an electronic card) to build from offline part transfer online marketing strategy, as far as possible transfer the line loss of traffic to online integrates online.

\section{Method}

The qualitative research method is particularly suitable for 
this study for the following three reasons. First of all, the purpose of this study is to answer the question of strategic planning for the catering industry in the context of coVID19, which belongs to the category of "how". Secondly, this paper observes and analyzes to describe and understand a specific case. Then, it turns the research into opinions, feelings, and experiences rather than emphasizing operational variables or answering questions with a verification hypothesis. This makes it more appropriate to collect data, observe results and study problems by analyzing the organizational environment rather than using quantitative methods. Third, the existing problems facing the catering industry in the context of coVID-19, the future direction of development and the measures that need to be implemented are emerging problems because there are too many uncertainties. So it is most appropriate to use systematic procedures to develop inductive leads to theory in response to this phenomenon.

The selection of CHONGQING RJ Restaurant as the object of the case study is based on the following three criteria. First, the enterprise is very unique and representative principle. RJ restaurant is a medium-sized private restaurant with characteristics similar to that of most restaurants facing difficulties under coVID-19, so it is used as a case study to represent this specific group; In addition, THERE is a strong backing behind RJ Restaurant - QJ Group Company, with enough money to operate RJ restaurant to have a plastic future. Therefore, the selection of CHONGQING RJ restaurant as the object of the case study follows the principle of uniqueness and representativeness of the case selection. The second is the principle of theoretical sampling. The case study method selects cases based on the need to fill existing theoretical gaps or develop new theories rather than statistical sampling. Although previous studies considered the importance of sustainable development of the catering industry, many early scholars proposed many possibilities for the future of the catering industry, but many of them were theoretical explanations under normal phenomena, and there was a lack of analysis under the coVID-19. This study takes the strategic planning of Chongqing RJ Restaurant under the coVID-19 as the research object and tries to open the "black box" to improve the operation level and strategic planning of enterprises under the coVID-19, which is helpful to improve relevant theories. Finally, in the competitive strategy studied in this paper, many people use a quantitative research method. However, for Chinese enterprises, China has its own particularity — different places have different implementation measures. RJ Restaurant in Chongqing can directly obtain first-hand data, so this case study method is more helpful for the depth and development of this study.

To sum up, this study followed the case study procedure, identified research questions, theoretical reviews, data collection, and data analysis. Through theoretical analysis and data analysis, the focus of the research is maintained to obtain new ideas and perspectives.

\section{Results}

\subsection{External analysis of the restaurant}

\subsubsection{PEST analysis}

PEST is a practical and straightforward macroenvironment analysis model that can not only analyze the macro environment, but also effectively identify various macro impact forces affecting the restaurant through its own characteristics and operating requirements.

Political factors_-At the beginning of this year, a sudden outbreak of the disease to call just a need for the catering industry was caught off guard. With China's policy of strict prevention and control, the epidemic was quickly contained. The restaurant industry has been forced to close to the later dispersed seating, the restaurant industry thus showed a rapid pace of recovery. The government has introduced policies, such as tax cuts and fees, to revive the stagnant economy.

Economic factors-According to the Evergrande research institute, the epidemic has caused a loss of about 500 billion yuan to the catering industry's retail sales in just seven days of the Spring Festival. During the epidemic, 93\% of catering enterprises chose to close their stores. Of those, 73 percent closed all their stores; $8 \%$ closed more than $80 \%$ of their stores; And 7\% closed less than half of their stores; Only $7 \%$ of catering enterprises continue to maintain all their stores due to group meals or stand-alone restaurants.

Social factors_—During the epidemic prevention and control period, small and medium-sized restaurants were mainly affected because of their low anti-risk ability. With the development of policies, the epidemic situation has been effectively controlled, and retaliatory consumption in the catering industry will appear at any time. Nevertheless, on June 12, 2020, a novel Coronavirus was detected in the salmon from the Seafood market of Fengtai District, Beijing. So far, the seafood market into the severe winter and the restaurant's food safety to the forefront.

Technical factors-The coVID-19 outbreak has given a strong boost to the takeaway market. Although the quality of food sold by diners in second - and third-tier cities is still questionable, it cannot be denied that the epidemic has accelerated the improvement of food market resources, systems and supporting facilities. In addition, food and beverage selections and menus will be more health-oriented, with nutrition and health care becoming the top priorities.

\subsubsection{Porter's five Forces analysis}

Porter's five Forces competitiveness model has been widely used in many industries, including the catering industry. This five competitiveness can determine the profitability and level of restaurants.

Bargaining power of suppliers-The seafood products are purchased in Hanoi and Beihai, with high concentration of suppliers and weak bargaining power. Unlike the inland seafood market, the restaurant has a small purchase scale, so its bargaining power is limited. However, 
suppliers of general ingredients, such as pork, beef, mutton, vegetables and so on, can substitute their products, so the conversion cost of catering is low. Therefore, RJ restaurant has a certain advantage in bargaining with general suppliers but not with seafood suppliers.

Buyer's bargaining power-There are no Sichuan seafood fusion dishes in RJ restaurant, and the brand conversion cost is high. Therefore, it is difficult for customers to find alternative catering enterprises, so the market competition is fierce and small. To sum up, these factors weaken consumers' bargaining power, who cannot lower their prices while demanding high-quality products and services. Therefore, there is still a certain margin for the profit of restaurants.

The threat of substitutes-At present, there is no alternative restaurant in the whole area, so to speak, it is the only one.

Threats from potential entrants_- RJ restaurant occupies an irreplaceable position in the catering industry in this region and is a force driving the growth of consumer demand in the whole district street. The restaurant has high technical content and high start-up capital, so the entry barrier is relatively high, and the market is not saturated. Therefore, the market potential is large, so there will inevitably be other competent competitors who want to share the market.

Analysis of existing industry competitors__-If regional restrictions are removed, RJ has a number of strong competitors. For example, LS restaurant serves authentic dishes that maintain the freshness of seafood and integrate the spicy taste of Chongqing people. BF restaurant is a seafood cafeteria with more than 200 kinds of dishes. Besides, the decoration is more magnificent and magnificent. SH restaurant, a popular specialty restaurant for 15 years ago, advocates environment-friendly handmade food. Dishes are served directly on the greasy paper on the table. The decoration style is a combination of pirate theme and western cowboy style, which is popular among young people and children. Therefore, the existing competitors have their own characteristics and shortcomings. In order to occupy a favorable position in the catering industry, RJ restaurant needs to have its own core competitiveness, such as outstanding characteristics, in addition to fresh food materials and a comfortable and elegant environment.

\subsection{Internal analysis of the restaurant}

\subsubsection{Organizational resource analysis}

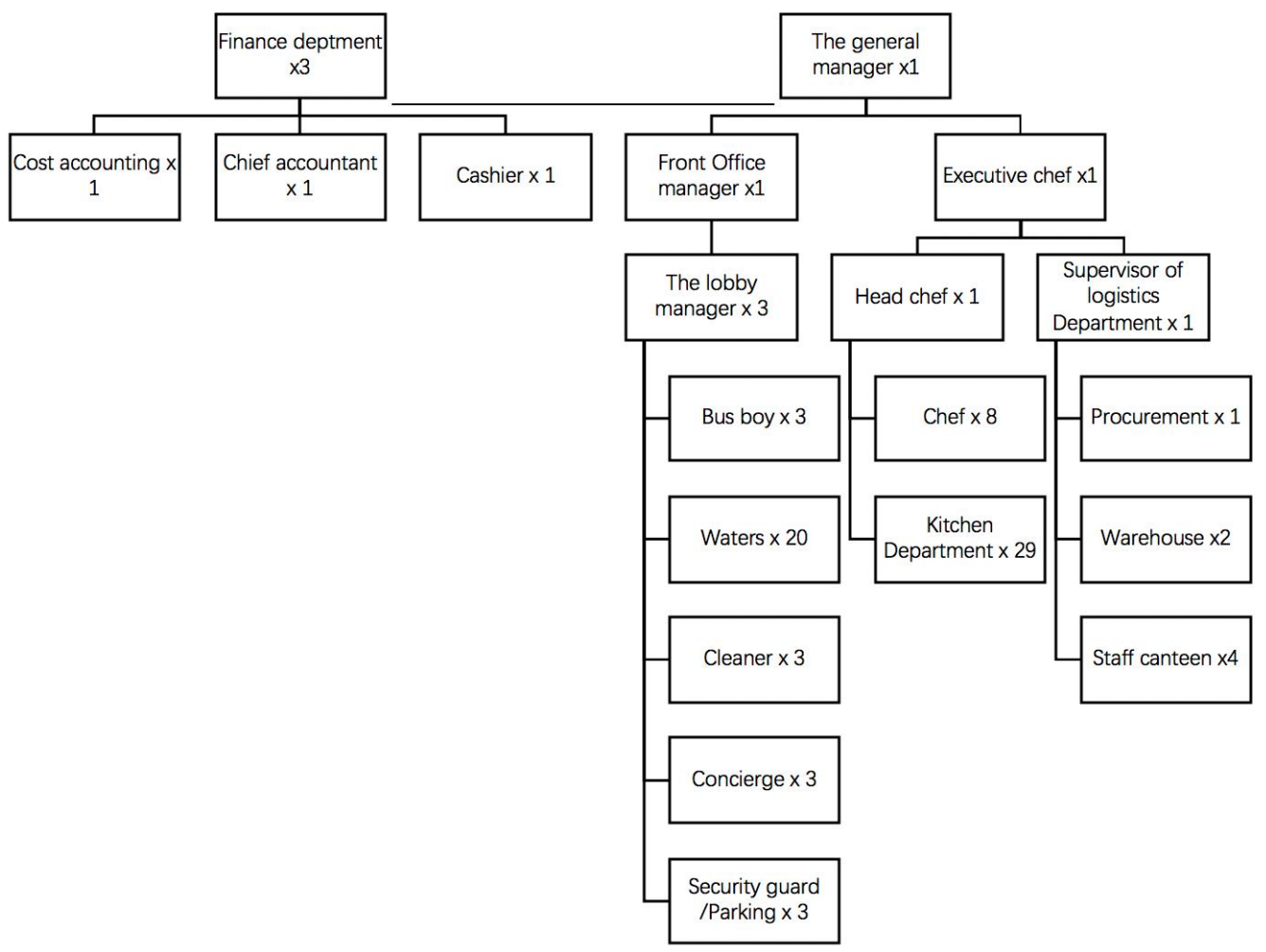

Figure 1. RJ restaurant employee Position Administration.

The organizational structure of RJ restaurant can be clearly seen in the figure above. The financial department is mainly responsible for summarizing the operating situation of the restaurant (collection and cash management), calculating the daily cost and making a statistical analysis of the cost ratio, and holding regular meetings to formulate strategies and goals; Strengthen cost control management, have moderate cash flow and 
minimize costs. The front office is responsible for the allocation of personnel in the front hall, the design of the site and the communication with the kitchen. The executive chef may assign the entire kitchen staff. The logistics department is responsible for the purchase of food materials, inventory management and staff canteen.

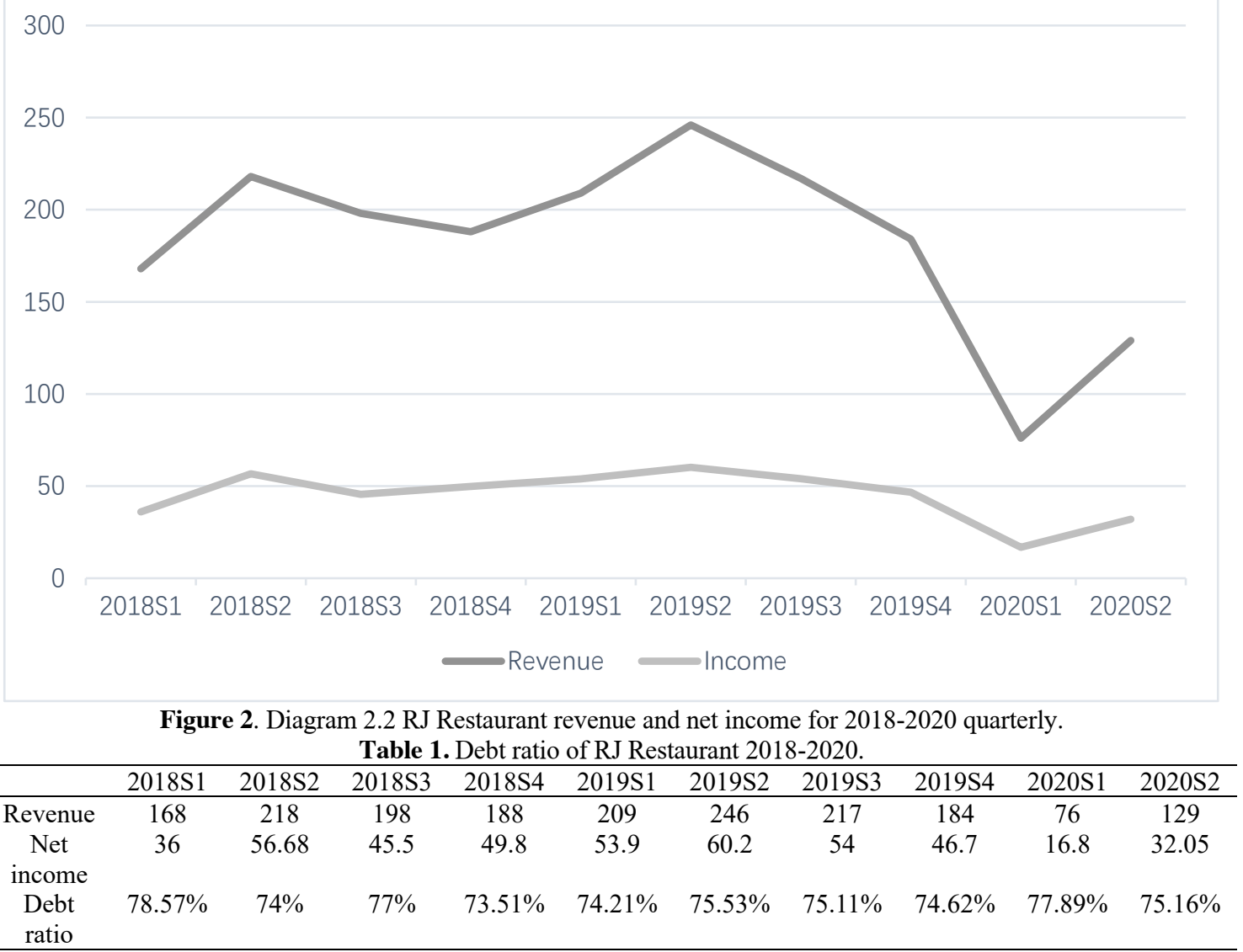

\subsubsection{Financial analysis}

As can be seen from figure 2, the first half of the year's revenue trend has been better than that of the second half since the restaurant opened in 2018. Moreover, it was obvious that the novel Coronavirus caused a hit to RJ restaurant at the beginning of 2020, which greatly reduced the turnover. According to the global Economic Data Network, the average debt ratio of China's catering industry in 2018 was $67.08 \%$. Compared with table 1, the debt ratio of $\mathrm{RJ}$ restaurants is higher than the average. The restaurant book has a high debt ratio, which indicates that the restaurant has more assets (or inventory); in other words, the restaurant has a greater financial risk.

\section{CONCLUSION}

The results obtained from the case analysis can clearly indicate that the financial risk of Chongqing RJ restaurant is relatively high, in other words, the restaurant is likely to go bankrupt. The catering industry is a livelihood industry, in addition to the employment issue, there is also an industrial chain behind it, which involves many fields such as food materials and drinks.

In the face of Covid-19, such a force majeure external environment, the government should support the catering industry. For restaurants, the government can give appropriate financial subsidies; If a catering enterprise is in difficulty and cannot pay tax on time, it may apply to the government for deferment of tax payment according to law. Besides, the government can share the cost of water and electricity to support the catering industry to the greatest extent to tide it over.

For the restaurant itself, it is more appropriate to choose the cost strategy and differentiation strategy. First of all, using intelligent robots to replace human resources can effectively reduce labor costs. Intelligence will gradually penetrate into the catering industry. There are several robot food delivery services in China. Many restaurants have begun to arm their restaurants with high technology, realizing automation from ordering food, ordering food, delivering food, and completing electronic payments. The enterprise can spend a high price to buy an automatic oven, automatic cooking noodle machine, automatic cooking machine and other advanced kitchen equipment, so that the kitchen will gradually enter the stage of modernization, mechanization, and intellectual development. These not only reduce the kitchen and service labor costs, solve the problem of production quality is not stable, the restaurant will have more space for front office operation, but also attract customers while improving marketing is very beneficial. In addition, the catering industry's future trend will be combined with the Internet and e-commerce economy in the era of digitization and refinement. The 
precipitation, recording, and analysis of consumer behavior data of catering enterprises through the Internet will enable the Internet to play the greatest supporting role in the catering industry. Customers' desire for personal experience is on the rise, and they want to get more tasteful, more personalized, and more satisfying catering services. Enterprises can create "customized" services based on the theme, purpose, grade and other factors required by customers through Internet data, so as to cater to customers' needs as much as possible. Taking Chongqing RJ restaurant as a case study, this paper may make up the theoretical gap of the catering industry strategy under coVID-19, point out the direction of economic entities and provide some policy Suggestions for the catering industry under COVID-19.

\section{REFERENCES}

1. Kelin Ye, 1998, The Development and Innovation of enterprise Competitive Strategy theory: A summary of the three main schools since the 1930s, Jianghai journal, p.28-32.

2. The relationship between strategic management and industry structure analysis. (n.p.).Retrieved April 10, 2018, from: http://www.hrxuexi.com/article-16941.html.

3. Porter's competitor Analysis model, (n.d.) from: https://wiki.mbalib.com/wiki/porter'scompetitoranal ysismodel.

4. Yi Li, 2013, Research on the Antagonism and Unity of Strategic Management School Contradictions Based on the Comparative analysis of value Innovation Strategy, Competitive Strategy and Resource and Ability Theory, Economic research guide, No.27, Serial No.209, from https://www.ixueshu.com/document/ca6c4f775fa642 b6318947a18e7f9386.html.

5. $\mathrm{Ke} \mathrm{Xu}$ and Erming $\mathrm{Xu}, 2002$, A Review and comparison between the School of Enterprise Resources and the School of Competence, Economic Management Journal, No.2 in 2002, from http://www.docin.com/p-1333981454.html.

6. Yingyi, Zhang, (n.d), Review and reflection on the school of Resources in strategic 